Assiut Scientific Nursing Journal

http://asnj.journals.ekb.eg

http://www.arabimpactfactor.com

\title{
Effect of Educational Program Regarding Brucellosis Among Blood Donors at Assiut University Hospital's Blood Bank
}

Fatma R. Khalaf ${ }^{1}$, Doaa M. Abd Elkareem ${ }^{2}$ \& Safaa R. Osman ${ }^{3}$.

1. Lecturer of Family and Community Health Nursing, Faculty of Nursing, Assiut University, Egypt.

2. Lecturer of Clinical Pathology, Faculty of Medicine, Assiut University, Egypt.

3. Lecturer of Family and Community Health Nursing, Faculty of Nursing, Assiut University, Egypt.

\begin{abstract}
Brucellosis is a serious community health problem and endemic disease in Egypt in both animal and human. Community health nurse had vital role to prevent \& control of brucellosis. Aims: to evaluate the effectiveness of the educational program about brucellosis among blood donors. Methodology: Quasi experimental design was used. This study was carried out at the main University hospital's blood bank in Assiut. The studied sample selected by simple random sample who was 300 blood donors. An interview questionnaire was used which included their socioeconomic characteristics. Also, pretest was done by questions regarding knowledge, attitude and their reported practices about brucellosis to assess the effectiveness of the educational program through immediate posttest. Blood sample was collected from all blood donors and analyzed by the enzyme linked immunosorbent assay (ELISA) test to detect the positive cases Results: According to their residence all the studied sample from rural areas. The prevalence of brucellosis was $16 \%$ among them. Regarding knowledge of studied blood donors about brucellosis, in pre test the mean score was $10.37 \pm 5.20$ while after implementing the educational program the mean score increased to $27.37 \pm 2.37$ with highly significant differences $(P$ value $=<0.001)$. The mean score of reported practices and attitude were $(1.9 \pm 1.14,13.31 \pm 2.05)$ respectively. Conclusion: Brucellosis is a community health problem in Assiut Governorate. The blood donors' knowledge, attitude and practices were mostly poor and after completion of the program a significant improvement were achieved in the blood donors' knowledge. Recommendation: Further researches are needed to update the individuals' knowledge, positive attitude and appropriate practices about brucellosis.
\end{abstract}

\section{Keywords: Blood Donors, Brucellosis \& Educational Program.}

\section{Introduction}

Brucellosis is a major re-emerging zoonotic disease and considered a community health concern in several developing countries and also reported in many developed countries with more than a half million infected human per year. Eradication of brucellosis occurred in several countries especially in Northern and Central Europe (Hegazy, Elmonir, Hosny, Hamid, \& Elbauomy, 2016). The mainstream of cases occur in the Mediterranean countries including Egypt (Aziz, 2013; AL-habaty\& Abuo-Gazia, 2015; Ran et al., 2019). In high-risk populations in Egypt, the human brucellosis' prevalence was determined to be as elevated as $8 \%$. Also, in another study conducted in Fayoum governorate, the actual human brucellosis cases was less than $6 \%$ (Hegazy et al., 2016). While, in a study conducted in Yemen, the sero-prevalence of brucellosis was from 0.3 to $32.3 \%$ (Al-Arnoot et al., 2018).

Brucellosis is identified as "Mediterranean fever" or "Malta fever", it can affect persons of all ages. It's considering one of the most globally zoonotic transmittable diseases. The bacterial agent of genus
Brucella (six species) was the responsible infective agent. The causative organisms which had greater risk for human infection were Brucella abortus, B. melitensis and B. suis. The organisms can affect cattle, sheep/goat, swine, and dogs (Dadar, Shahali, \& Whatmore, 2019) (Lakew, Hiko, Abraha, \& Hailu, 2019).

The routes of spreading to human being are through contact with sick animals, ingestion of infected milk and milk product as intake of unpasteurized milk and fresh cheese. Also, it can be transmitted through meat, or raw vegetables which contaminated with infected animal's discharge. Brucellosis was considered an occupational hazard to personnel who was treating with the animals as veterinarians, butcher workers and farmers (Golshani \& Buozari, 2017). Person to person transmission is possible through blood donation and organ transplantation(Al-Arnoot, Abdullah QYM, Alkhyat, Almahbashi, 2018) \& (Workalemahu, Sewunet, \& Astatkie, 2017a).

The human infected with brucella can complain from acute febrile illness character which included elevated temperature, sweats, tiredness, malaise, loss of appetite, weight loss, headache, arthralgia and backache (Workalemahu et al., 2017a). 
If untreated, the pattern of the fever increased and declined over several days ("undulant fever"). The diseases can progress from acute phase to chronic one with relapse. Incubation period can take from two to three weeks (Dadar et al., 2019).

Brucellosis complication can include different body sites and many disease as Osteoarticular disease. Besides affecting the healthy life in humans, it's causes considerable economic burden of the family as increased cost of treatment, loss of work or income loss due to illness, and Disability Adjusted Life Year (DALY) burden. Brucellosis caused a significant threat of spontaneous abortion and infant' intrauterine transmission throughout pregnancy (Gurrappanaidu et al., 2016). Diagnosis of brucella can only be confirmed by laboratory tests as ELISA which was considered an effective diagnosis (Turgut, Haddad, \& De Divitiis, 2015).

there was lacking of knowledge about brucellosis mostly in Asia and Africa according to systematic review of 79 studies to assess the knowledge about brucellosis in different communities(Lakew et al., 2019) \& (Zhang, Zhou, Huang, \& Guan, 2019) (Ntirandekura, Matemba, Ngowi, Kimera, \& Karimuribo, 2018) Knowledge, attitude and practice elevation about brucellosis among the risky groups is an urgent considerable need for the prevention of brucellosis (Arif Sh, Thomson, Hernandez-Jover, McGill, Warriach, 2017).

Health education about human brucellosis prevention; based on occupational sanitation and food hygiene; is the main duties of health team especially community health nurses. Nurses in this field often serve as leaders, educators, advocates and researchers, all in addition to their nursing roles. Many public health nurses practice, study, develop and lead public health campaigns. Within local communities, nurses are also needed to teach preventive health practices so more people can live healthy, productive lives. Educational Health program is playing an important role in prevention of brucellosis among all people in the community (Aziz, 2013) \& (Warwick \& Corning, 2013).

\section{Significance of the study}

WHO reported that there were 500000 cases yearly throughout the world (Shakurnia, Qasemzadeh, Afra, \& Kohshour, 2014). The human brucellosis' prevalence was determined to be $8 \%$ in Egypt (Hegazy et al., 2016) It is still endemic and serious public health problem in Egypt in both animal and human which causes consider economic loss in livestock and humans. Brucellosis usually was neglected or misdiagnosed. Regular screenings for brucellosis through serological investigation of blood donation is very important to detect its prevalence, early diagnosis, and treatment. So, health education programs should be given to raise knowledge, attitude and practice (KAP) levels which is the main duties of health team especially nurses to prevent \&control brucellosis in Assiut governorate.

Aim of the study

To evaluate the effectiveness of the educational program about brucellosis through:

1. Assessing knowledge, attitude and practice of blood donors about brucellosis.

2. Detecting the brucellosis' prevalence among blood donors

3. Implementing and evaluate the efficiency of the educational program about brucellosis.

\section{Hypothesis}

Implementation of the educational program can improve knowledge, attitude and practice of blood donors regarding brucellosis.

\section{Methodology}

Research design

Quasi experimental research design was applied.

Research setting

The study was performed at the main University hospital's blood bank in Assiut. All studied participants were from rural areas.

Sample size

Simple random sampling was used to collect data from blood bank through closed envelope method; 30 pieces of paper representing names of the collected blood donors which are placed in a box, then 10:20 paper were chosen without any bias during 2 days/ week. Sample size was calculated using the previous reported prevalence of brucellosis (8\%) according to Samaha et al, 2008 (Samaha, Al-Rowaily, Khoudair, \& Ashour, 2008). By using software open access Epi/Info version 7 with $99 \%$ confidence level. It was found to be 196 blood donors. Studied population was increased to 300 blood donors to avoid errors from testing.

\section{Tools of the study}

An interview questionnaire was divided into two tools which included:

\section{Tool (I): it was contained four parts}

Part one: Socio-demographic characteristics

It was included personal characteristics like name, age, sex telephone number and Socio Economic Status Scale which designed by Abd-El-Tawab (2012) to assess socioeconomic status of the family. It consists of 4 dimensions, which include level of education, occupation, total family monthly income, and Life style of the family. The total score was divided into three classes as high, moderate and low socioeconomic level.

Part two: knowledge regarding brucellosis

It assessed the knowledge regarding brucellosis in pre and post implementing the instructional program. 
Knowledge portion contained twelve questions as definition, causes, signs and symptoms, modes of transmission...etc. Total score was 35, questions were scored as one mark for correct answer and 0 mark for wrong, no answer or in refusing to answer. Brochure was designed and distributed for the blood donors after completing the program.

Part three: Reported practices about treating with animals

This tool consisted from eight questions. It included questions regarding milk pasteurization, animal dung, disposing the dead and aborted animals, and vaccination of animals. Total score was 9, one mark for correct answer and zero mark for wrong, and don't know.

\section{Part four: Attitude toward brucellosis}

It consisted from eleven items which its response based on a three-point Likert Scale (agree, uncertain and disagree). Items were scored (2,1and 0$)$ respectively; the score was reversed for negative statements. Total score was calculated which ranged from 0: 22, the higher the mean score the better the attitude toward brucellosis.

Tool II: The enzyme linked immunosorbent assay (ELISA)

After finishing the interview form, the researchers were taken $3 \mathrm{ml}$ blood from all participants with considering all a septic technique. The blood samples were stamped with a specific number and date. The samples were preserved at $4{ }^{\circ} \mathrm{C}$ for 24 hours. Later, they were transited on low temperature to the laboratory. Blood samples investigated for Brucella $\operatorname{IgA}$ IgM and $\operatorname{IgG}$ antibodies by using the accessible ELISA kits according to the standard procedure. ELISA IgG test was more trustworthy than ELISA IgM test in diagnosis of human brucellosis by using a cut-off of $0.32 \mathrm{IU} / \mathrm{ml}$, most sensitivity $(99.2 \%)$ and most specificity (100\%) for ELISA IgG test.

\section{Reliability of a tool}

The internal consistency of the responses for each scale and the total tool were calculated by using Cronbach $\alpha$ coefficient that was 0.820 .

\section{Validity of tool:}

Questionnaire was examined and reappraised by three of specialists in the field of Community Health Nursing and Clinical pathology staff at Assiut University who reviewed the instruments for clarity, relevance, comprehensiveness, understanding and applicability.

Field work

\section{Administrative phase}

An official letter approval was obtained from the Dean of the Faculty of Nursing, Assiut University and directed to the manager of blood bank to complete the study. The letter involved a permission to carry out the study.

\section{Educational program construction}

The educational program conducted according to the following four stages:

\section{Assessment stage}

Investigators prepared the questionnaire based on the relevant article and literature review which designed to collect data and develop educational plan to increase blood donors' knowledge and improve their attitude and practice regarding brucellosis.

Planning stage

Objective of the program

To evaluate the effectiveness of the educational program about brucellosis among blood donors:

\section{Content of the program}

1. Introduction, definition, signs and symptoms of brucellosis.

2. Mode of transmission and prevention of brucellosis.

3. Milk pasteurization.

4. How to treat with animal dung and disposing the dead and aborted animals (uses of protective measures).

5. Importance of animals vaccination.

The program arrangement

The researchers prepared the place of lecture, meeting, brochure, etc. the program conducted at blood bank. Time of teaching was determined based on suitable time of a participant and the coordination between the researchers and blood donors. The researchers used plain teaching styles like: lecture, discussion. The media handouts regarding brucellosis were given to all participants after finishing the session.

\section{Implementation stage}

During meeting, the researchers illustrate the goal of the work to the blood donors. Pretest was done prior the meeting to evaluate the recipients' knowledge, attitude and their reported practices. The time needed to complete the pretest was ranged from 20-30 minutes. Every participant takes two sessions for one hour to each to complete the program contents. Session one included (Introduction, definition, signs and symptoms, mode of transmission and prevention of brucellosis). Session two included (milk pasteurization and how to treat with animal dung and disposing the dead and aborted animals (uses of protective measures), and importance of animals vaccination). This study performed in duration from the first of January to the end of June 2018, two days/ week.

Evaluation stage

The evaluation was done through posttest which done immediately after implementing and completing the course to assess participants' level of knowledge. Posttest implemented by repeating the same format of 
pre test to determine the effect of an educational program.

\section{Pilot study}

Pilot study was carried out before starting of data collection on (30) blood donors. The questionnaire required about 20-30 minutes to complete. The aim of this study was to test the clarity of the tools and to determine the required time to complete the questionnaire. The pilot study was excluded.

\section{Ethical issues}

Study suggestion was confirmed from ethical committee in the Faculty of Nursing, Assiut University. No danger was found during implementation of the study. This study was following general moral concepts in clinical study. Written consent gained from blood donors that were willing to share in the study after clarifying the reality and goal of the study. Privacy was confirmed. Research participant had the choice to reject to join or dropped out from the research at any time they want and in the absence of any reason. All positive cases were informed and referred to a specialist to receive their treatment.

\section{Statistical analysis}

The data were tested for normality using the Anderson-Darling test and for homogeneity variances prior to further statistical analysis. Categorical variables were described by number and percent $(\mathrm{N}, \%)$, where continuous variables described by mean and standard deviation (Mean, $\mathrm{SD})$. Chi-square test and fisher exact test used to compare between categorical variables where compare between continuous variables by t-test land ANOVA TEST.A two-tailed p $<0.05$ was considered statistically significant. All analyses were performed with the IBM SPSS 20.0 software

\section{Results}

Table (1): Distribution of blood donors according to their socio demographic characteristics at Assiut University's blood bank.

\begin{tabular}{|l|c|c|}
\hline \multicolumn{1}{|c|}{ Socio-demographic } & No. (300) & \% \\
\hline Age group & & 36.7 \\
\hline 18- years & 110 & 31.3 \\
\hline 28- years & 94 & 32.0 \\
\hline$>38$ years & 96 & \\
\hline Gender & & 40.0 \\
\hline Male & 120 & 60.0 \\
\hline Female & 180 & \\
\hline Marital Status & & 26.0 \\
\hline Single & 78 & 73.3 \\
\hline Married & 220 & 0.7 \\
\hline Widow & 2 & \\
\hline Education Level & & 17.3 \\
\hline Illiterate & 52 & 21.3 \\
\hline Read and write & 64 & 14.7 \\
\hline Primary & 44 & 11.3 \\
\hline Preparatory & 34 & 28.7 \\
\hline Secondary & 86 & 4.7 \\
\hline University & 14 & 2.0 \\
\hline Post graduate & 6 & \\
\hline Socio economic level & & 11.3 \\
\hline Low & 34 & 73.3 \\
\hline Middle & 220 & 15.4 \\
\hline High & 46 & \\
\hline
\end{tabular}


Table (2): Distribution of blood donors according to their reported practices about brucellosis at Assiut University's blood bank $(n=300)$

\begin{tabular}{|c|c|c|}
\hline Items & No & $\%$ \\
\hline \multicolumn{3}{|l|}{ Own animals at home } \\
\hline Yes & 272 & 90.7 \\
\hline No & 28 & 9.3 \\
\hline \multicolumn{3}{|c|}{ Assisting with the birth of animals at home } \\
\hline The housewife & 98 & 32.7 \\
\hline Husband & 48 & 16.0 \\
\hline Housewife and husband & 102 & 34.0 \\
\hline Veterinarian & 24 & 8.0 \\
\hline \multicolumn{3}{|l|}{ Disposal of dead animals } \\
\hline Buried & 102 & 34.0 \\
\hline Fed to dogs & 22 & 7.3 \\
\hline Throw away in canal & 176 & 58.7 \\
\hline \multicolumn{3}{|c|}{ Protective measures used with aborted animals and their wastes } \\
\hline Using gloves & 53 & 17.7 \\
\hline Washing hands & 97 & 32.3 \\
\hline Didn't use any protective measures & 150 & 50.0 \\
\hline \multicolumn{3}{|l|}{ Boiling the milk } \\
\hline Yes & 232 & 77.3 \\
\hline No & 68 & 22.7 \\
\hline \multicolumn{3}{|l|}{ Discard of animals' excreta } \\
\hline Bury it & 68 & 22.7 \\
\hline Throw it in front of the house & 50 & 16.7 \\
\hline Used as fertilizer & 150 & 50.0 \\
\hline \multicolumn{3}{|c|}{ Notifying to the Veterinary Unit about sick animals } \\
\hline Yes & 40 & 13.3 \\
\hline No & 232 & 77.3 \\
\hline \multicolumn{3}{|l|}{ Vaccination of animals } \\
\hline Yes & 14 & 4.7 \\
\hline No & 258 & 86.0 \\
\hline \multicolumn{3}{|l|}{ Source of information about brucellosis } \\
\hline The media & 182 & 60.7 \\
\hline Doctor and nurses & 98 & 32.7 \\
\hline Parents and relatives & 66 & 22.0 \\
\hline Neighbors & 24 & 8.0 \\
\hline Studying & 14 & 4.7 \\
\hline Internet and social media & 10 & 3.3 \\
\hline
\end{tabular}




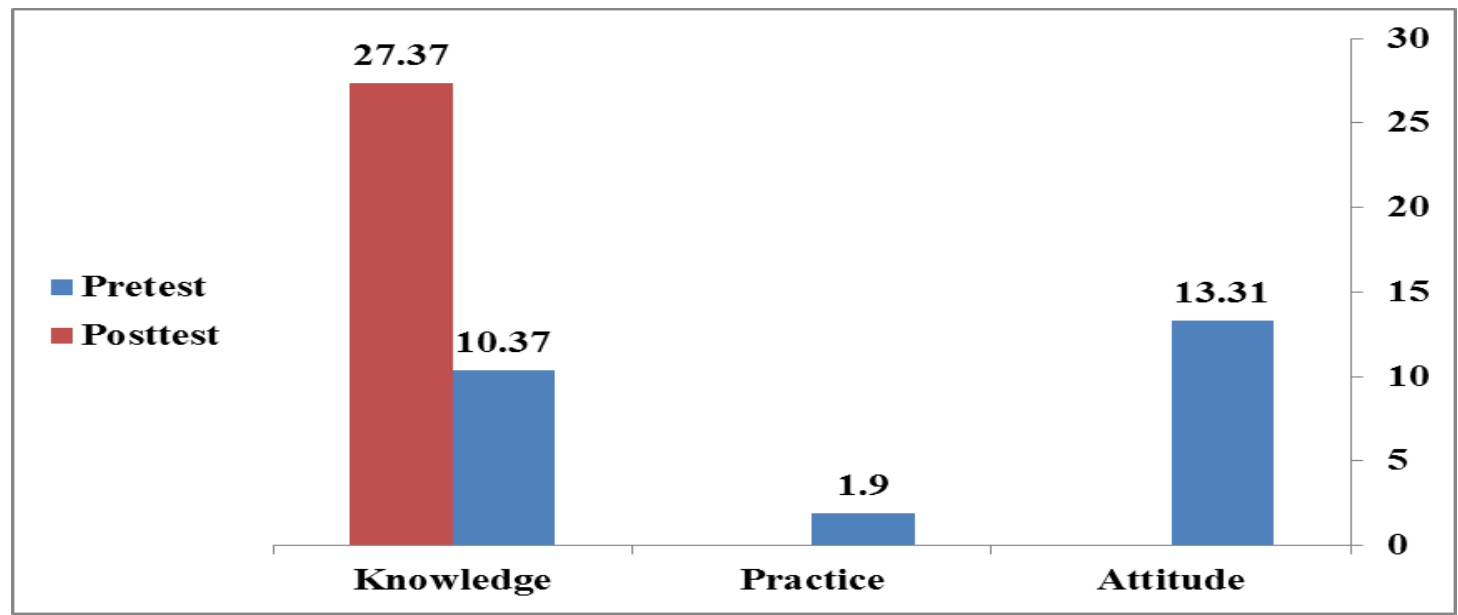

Figure (1): Overall mean score of Knowledge, attitude and reported practice regarding brucellosis among blood donors at Assiut University hospital's Blood Bank.

Table (3): Relationship between socio demographic characteristics and knowledge mean score (pre and posttest), attitude and reported practice about brucellosis at Assiut University's blood bank

\begin{tabular}{|c|c|c|c|c|}
\hline \multirow{3}{*}{ Items } & \multicolumn{2}{|c|}{ Knowledge score } & \multirow{2}{*}{ Attitude score } & \multirow{2}{*}{ Practice score } \\
\hline & Pre education & Post education & & \\
\hline & Mean \pm SD & Mean \pm SD & Mean \pm SD & Mean \pm SD \\
\hline \multicolumn{5}{|l|}{ Age group } \\
\hline 18- years & $9.47 \pm 5.08$ & $26.96 \pm 2.87$ & $13.47 \pm 1.98$ & $2.11 \pm 1.15$ \\
\hline 28- years & $9.7 \pm 5.04$ & $27.43 \pm 2.12$ & $13.21 \pm 1.97$ & $1.7 \pm 1.17$ \\
\hline$>38$ years & $12.04 \pm 5.13$ & $27.31 \pm 1.92$ & $13.21 \pm 2.22$ & $1.84 \pm 1.06$ \\
\hline P.value & $0.001 * *$ & 0.344 & 0.568 & 0.033* \\
\hline \multicolumn{5}{|l|}{ Gender } \\
\hline Male & $10.45 \pm 5.27$ & $27.33 \pm 2.01$ & $13.13 \pm 2.31$ & $2.09 \pm 1.03$ \\
\hline Female & $10.31 \pm 5.16$ & $27.14 \pm 2.59$ & $13.42 \pm 1.86$ & $1.77 \pm 1.19$ \\
\hline P.value & 0.821 & 0.500 & 0.233 & 0.015 \\
\hline \multicolumn{5}{|l|}{ Education Level } \\
\hline Illiterate & $9.08 \pm 5.05$ & $27.04 \pm 3.47$ & $13.35 \pm 2.2$ & $1.81 \pm 1.09$ \\
\hline Read and write & $13.88 \pm 5.4$ & $27.63 \pm 1.42$ & $13 \pm 2.15$ & $1.77 \pm 1.24$ \\
\hline Primary & $9.86 \pm 3.99$ & $27.18 \pm 2.3$ & $13 \pm 1.9$ & $1.82 \pm 1.17$ \\
\hline Preparatory & $12.18 \pm 4.6$ & $27.94 \pm 0.42$ & $12.53 \pm 1.78$ & $2.12 \pm 0.84$ \\
\hline Secondary & $8.23 \pm 4.27$ & $26.77 \pm 2.42$ & $14.12 \pm 1.89$ & $1.93 \pm 1.21$ \\
\hline University & $11.14 \pm 6.21$ & $26.86 \pm 3.39$ & $13.43 \pm 1.65$ & $2.57 \pm 0.76$ \\
\hline post graduate & $6.33 \pm 1.86$ & $28 \pm 0.89$ & $11 \pm 0$ & $1.33 \pm 1.03$ \\
\hline P.value & $0.000 * *$ & 0.149 & $<0.001 * *$ & 0.166 \\
\hline \multicolumn{5}{|l|}{ Marital Status } \\
\hline Single & $10.23 \pm 5.73$ & $27.72 \pm 1.4$ & $13.33 \pm 1.99$ & $2.37 \pm 1.03$ \\
\hline Married & $10.4 \pm 5.03$ & $27.04 \pm 2.62$ & $13.27 \pm 2.07$ & $1.72 \pm 1.13$ \\
\hline Widow & $12 \pm 0$ & $28 \pm 0$ & $16 \pm 0$ & $3 \pm 0$ \\
\hline P.value & 0.879 & 0.083 & 0.173 & $<0.001 * *$ \\
\hline \multicolumn{5}{|c|}{ Socio economic level } \\
\hline Low & $11.88 \pm 5.99$ & $27.94 \pm 0.65$ & $13.12 \pm 2.6$ & $1.88 \pm 1.04$ \\
\hline Middle & $10.32 \pm 5.19$ & $27.25 \pm 2.39$ & $13.3 \pm 1.95$ & $1.96 \pm 1.14$ \\
\hline High & $9.48 \pm 4.41$ & $26.52 \pm 2.89$ & $13.48 \pm 2.11$ & $1.59 \pm 1.17$ \\
\hline P.value & 0.119 & $0.027 *$ & 0.738 & 0.124 \\
\hline
\end{tabular}

Independent $T$ - test ${ }^{*}$ Significant difference at p. value $<0.01$

Anova test *Significant difference at $p$. value $<0.05$, **Significant difference at $p$. value $<0.01$ 


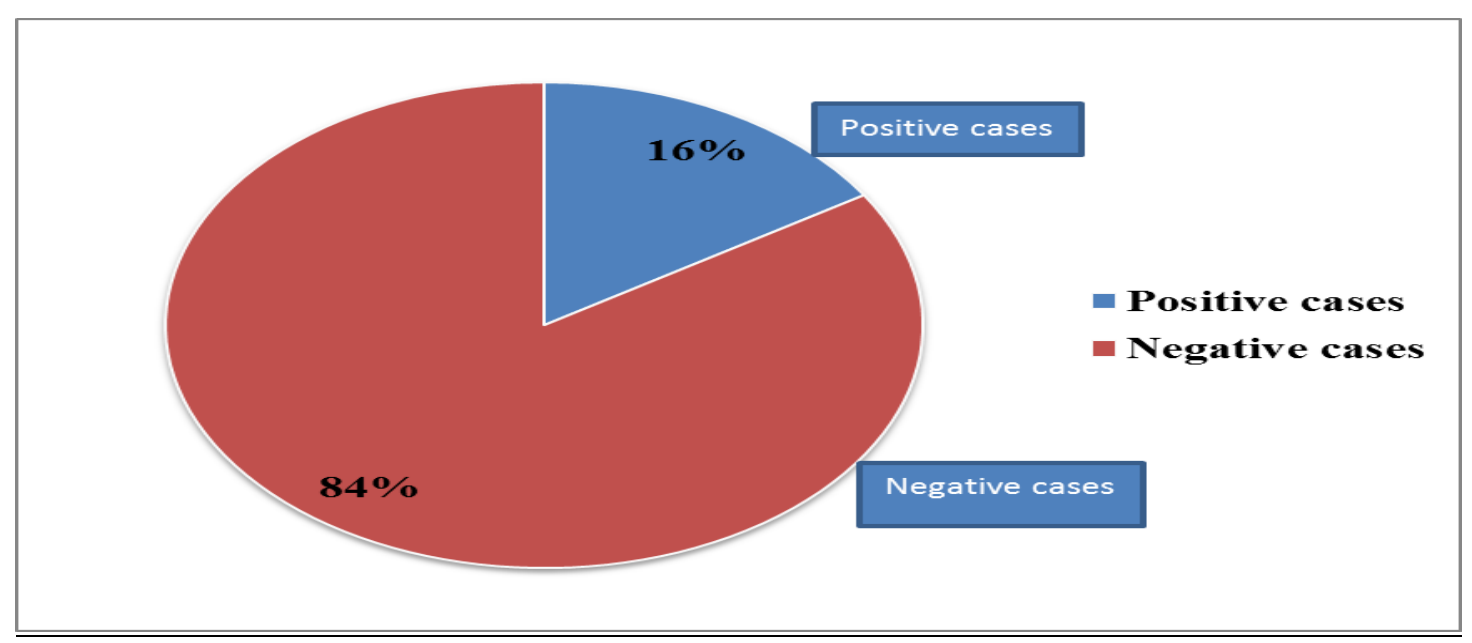

Figure (2): Sero-prevalence of brucellosis among blood donors at Assiut University hospital's Blood Bank.

Table (1): Showed that three fifths of the studied sample $60.0 \%$ was female, more than one third of them $31.3 \%$ their ages ranged from 18: 28 years. less than three quarters of them $(73.3 \%)$ are married and more than one quarter (28\%) had secondary education. Regarding socioeconomic level, less than three quarters of the respondents $(73.3 \%)$ was in middle level

Table (2): Cleared the distribution of blood donors according to their reported practices about brucellosis at Assiut University's blood bank. It revealed that $90.7 \%$ of them owned animals at their homes, only $8.0 \%$ called veterinarian in assisting with the birth of animals, more than half of them (58.7\%) throw the dead animals away in canal, half of the studied blood donors $(50.0 \%)$ didn't use any protective measures with aborted animals and their wastes and used the animals' excreta as fertilizer. Also, $77.3 \%$ of them boiled the milk and $86.0 \%$ of them didn't vaccine the animals. Also, table (2) cleared that media, doctors and nurses, parents and relatives were their main sources of information $(60.7 \%, 32.7 \%, 22.0 \%)$ respectively.

Regarding knowledge of studied blood donors about brucellosis figure (2) showed that, in pretest the mean score was $10.37 \pm 5.20$ while after implementing the educational program the mean score increased to $27.37 \pm 2.37$ with highly significant differences ( $\mathrm{P}$ value $=<0.001)$. The reported practices were $1.9 \pm 1.14$ (range 0-5) while their attitude was $13.31 \pm 2.05$.

Table (3): Revealed that there was highly statistically significant difference between age, level of education and knowledge mean score in pre education ( $\mathrm{P}$ value $=0.001,0.000)$ respectively, while there was statistically significant difference between socioeconomic level and knowledge mean score in post education $(\mathrm{P}$ value $=0.027)$. Also, it showed that there was highly significant difference between level of education and attitude mean score ( $\mathrm{P}$ value $=<0.001)$. According to the reported practices, it found that there was highly significant difference between age, marital status and practice mean score $(\mathrm{P}$ value $=0.003,<0.001)$ respectively .

Figure (2): Showed the sero-prevalence of brucellosis among blood donors at Assiut University hospital's Blood Bank. It revealed that $16 \%$ of the blood donors had brucellosis

\section{Discussion}

This is the first study of KAP associated with brucellosis among blood donors in Assiut, this study aimed to improve knowledge, attitude and practice of blood donors regarding brucellosis and to estimate the sero-prevalence of brucellosis among them.

In referral to personal characteristics of the participated blood donors, two fifths of them were aged 18 or less than 30 years. This observation in consist with the (Workalemahu et al., 2017b) who conducted a study under title Seroepidemiology of Human Brucellosis Among Blood Donors in Southern Ethiopia; and observed that nearly of three quarters of the studied participants were in the age group 16-30 years old. According to marital status nearly of three quarters of the studied sample were married while more than one quarter was single. These results agreed with a study titled Seroprevalence of Brucellosis among Farmers and Veterinary Technical Staff in the Central States of Peninsular Malaysia, Bamaiyi et al., (2017) who found that $77.80 \%$ of the respondents were married and $22.20 \%$ were single. According to place of residence; $100 \%$ of the participated blood donors were from rural area. This result disagreed with Sofian et al., (2013) who screening of family members of patients with acute brucellosis in an endemic area of Iran and reported that $11.9 \%$ of studied sample were living in rural. 
Concerning to level of education; more than one quarter of the blood donors in the current study had secondary education. According to a study conducted under title Knowledge, attitudes and practices (KAP) relating to brucellosis in smallholder dairy farmers in two provinces in Pakistan, the current data disagree with Arif et al., (2017) who found that $46 \%$ of respondents had no formal education. Regarding socioeconomic status; less than three quarters of blood donors in the present study were in the middle level. Contrary to findings Bamaiyi et al., 2017 who found that $84.53 \%$ of sample had low level.

Regarding the prevalence of brucellosis, $16 \%$ of blood donors in the current study were infected with brucellosis. This result disagreed with Al-Arnoot et al., 2018 who observed that in Yemen the prevalence was $2.2 \%$ in males and $1.6 \%$ in females. In a study conducted under title sero-prevalence and community awareness on the risks associated with Livestock and Human brucellosis in selected districts of Fafan Zone of Ethiopian-Somali National Regional State, it revealed that from the 211 human serum samples 2.4\% were positive (Lakew et al., 2019). Moreover, the study conducted in Ethiopia, found that $10.6 \%$ of the blood donors were positive (Workalemahu et al., 2017b). It might explain by most of the blood donors from the rural area in Assiut Governorate. Also, most of them owned animals and had poor practice while dealing with it.

According to mean score of knowledge of the blood donors about brucellosis; $10.37 \pm 5.20$ was in pretest while became $27.37 \pm 2.37$ in posttest. This observation agreed with Marin et al., 2017, who found that overall knowledge of respondents was low in South Sudan under title Knowledge, Attitude and Practices of Brucellosis among Slaughterhouse and Community Animal Health Workers in Wau, Western Bahr el Ghazal State. Also, the result consistent with a study conducted by Zhang et al., (2019) under title: brucellosis awareness and knowledge in communities worldwide: A systematic review and meta-analysis of 79 observational studies who found that there was insufficient awareness about brucellosis and improving public knowledge about brucellosis are urgently needed.

These results cleared that, there was statistically significance differences between mean score of knowledge and age, preparatory education and low social class in pretest. This finding consistent with Marin et al., (2017) who reported that knowledge of brucellosis was significantly associated with age, marital status, education, occupation and duration in work.

The present study showed that the most favored mode of receiving information on brucellosis was through mass media mentioned by less than two thirds of blood donors. This findings similar to the study in Kenya found main source of information to be from the local FM radio stations Obonyo\& Mark, Gufu, (2015).

The findings in this study showed that mean score of attitude of the blood donors about brucellosis; $13.31 \pm 2.05$ was in pretest. These findings were similar to the study in Kenya which found unfavorable attitude towards brucellosis Obonyo, Mark, Gufu, (2015).

The present study revealed that, there was significant relation between educational level and attitude. This finding inconsistent with (Marin et al., 2017 \& Marin et al., 2017)who reported that their wasn't significantly associated between educational level and attitude.

The present data showed that mean score of practice blood donors about brucellosis was $1.9 \pm 1.14$. The present data consistent with Obonyo \& Mark, 2015 who observed that there was poor practices towards brucellosis among participants.

The current data cleared that, there was significant relation between age, marital status and practice which was contrary to Marin et al., (2017) Based on results of this study, more than one third of studied sample mentioned that the housewife and homeowner were responsible for help of animal during birth. This findings contrast with Lakew et al., (2019) who reported that milking of animals was performed mainly by house wives in Ethiopian-Somali National Regional State.

In the current study, more than half of blood donors reported that they were thrown the dead animal on canal. This results in the same line with Musallam et al., (2015) who reported that $52 \%$ of participants were throwing aborted fetus in water canals. Also the current results was disagree with Arif et al., 2017 who found that more than one third of participants were throwing aborted fetus and placental membrane in dung piles.

Regarding protective measures using by blood donors when dealing with abortus animal and the waste of infected animal; more than one third, less than one third and less than one fifth of all participants stated that used nothing, washing hands and using gloves respectively. The present study contradicted with Musallam et al., (2015) who found that less than six percent of participants wearing protective gloves when disposing aborted fetus.

More than three quarters of blood donors mentioned they boiling the milk before using it for different purposes. This result similar with Musallam et al., (2015) who found that less than three quarters of participants were boiling milk before consumed it. While this findings in contrast with the study 
conducted in Ethiopia which revealed that the majorities consume raw milk (Lakew et al., 2019). About half of studied sample used the animal excreta as fertilizer the implant. More than three quarters of participants not notifying the veterinary unit when the animal is sick. It attributed by the owners' fear of undesirable decision of the veterinary unit on their herds as dispose of infected animals. This finding wasn't similar to Rajala, (2016) who found that less than half of respondent call veterinarian about animal health issues

Regarding vaccination of animals; the majority of studied sample reported that wasn't vaccinating your animals. It might explain by the absence of awareness for livestock owners about methods of brucella prevention. This current data similar with Musallam et al., (2015) who reported that, the majority of the respondents didn't vaccinate the animal.

\section{Conclusion}

In the light of the study results, it can be concluded that there was a positive sero-prevalence cases with brucellosis. The blood donors' knowledge, attitude and practices were mostly poor while after implementation of the educational program a significant improvement were achieved in the blood donors' knowledge and practice.

\section{Recommendation}

1. Abroad health education program about brucellosis should be given to health care providers especially nurses by using various educational media.

2. Serology of the blood about brucellosis in the blood bank should be done especially among high risk population such as farmers.

3. Further researches are needed to update the individuals' knowledge, positive attitude and appropriate practices about brucellosis.

\section{Acknowledgments}

The researchers would like to thank all participated blood donors and technician in the blood bank.

Funding: None

Competing interests: None declared.

\section{References}

1. Al-Arnoot S., Abdullah Q., Alkhyat S., Almahbashi A., (2018): Human and Animal Brucellosis in Yemen. Advances in Biotechnology \& Microbiology, 4(1), 3-6. https://doi.org/10.19080/aibm.2017.04.555630

2. Arif S., Thomson P., Hernandez-Jover M., McGill D., Warriach H., (2017): Knowledge , attitudes and practices ( KAP) relating to brucellosis in smallholder dairy farmers in two provinces in Pakistan. PLoS ONE, 12(3), 1-
19.

https://doi.org/https://doi.org/10.1371/journal. pone.0173365 Editor:

3. Aziz, K., (2013): Assessment of Nurse's knowledge and their Roles of Health Education in Primary Health Care Centers Regarding Prevention from Brucellosis in Erbil City. Medical Journal of Babylon, 10(4), 817-826. Retrieved from https://www.iasj.net/iasj?func=article \&aId $=81$ $254 \% 0 \mathrm{D}$

4. Bamaiyi, P., Hassan, L., Khairani-Bejo, S., Zainalabidin, M., Adzhar, A., (2017): Seroprevalence of Brucellosis among Farmers and Veterinary Technical Staff in the Central States of Peninsular Malaysia. Sains Malaysiana, 46(6), 933-943. https://doi.org/10.17576/jsm-2017-4606-13

5. Dadar, M., Shahali, Y., \& Whatmore, A., (2019): Human brucellosis caused by raw dairy products: A review on the occurrence, major risk factors and prevention. International Journal of Food Microbiology, Vol. 292, pp. 39-47.

https://doi.org/10.1016/j.ijfoodmicro.2018.12. 009

6. Golshani, M., \& Buozari, S., (2017): A review of brucellosis in Iran: Epidemiology, risk factors, diagnosis, control, and prevention. Iranian Biomedical Journal, Vol. 21, pp. 349359.

https://doi.org/10.18869/acadpub.ibj.21.6.349

7. Gurrappanaidu, G., Shome, R., (2016). Assessment of brucellosis knowledge, attitude and practice among veterinarians in India. Journal of Experimental Biology and Agricultural Sciences, 4(Spl-3-ADPCIAD), S83-S94. https://doi.org/10.18006/2016.4(Spl3-ADPCIAD).S83.S94

8. Hegazy, Y., Elmonir, W., Hosny, N., Hamid, A., \& Elbauomy, E. M. (2016). Seroprevalence and "Knowledge , Attitudes and Practices " ( KAPs ) survey of endemic ovine brucellosis in Egypt. Acta Veterinaria Scandinavica, 1-7. https://doi.org/10.1186/s13028-015-0183-2

9. Lakew, A., Hiko, A., Abraha, A., \& Hailu, S. M. (2019). Sero-prevalence and community awareness on the risks associated with Livestock and Human brucellosis in selected districts of Fafan Zone of Ethiopian-Somali National Regional State. Veterinary and Animal Science, 7, 100047. https://doi.org/10.1016/J.VAS.2019.100047

10. Marin, P. M., Am, S., Tumwine, G., Kankya, C., Nasinyama, G., \& As, J. (2017). 
Knowledge , Attitude and Practices of Brucellosis among Slaughterhouse and Community Animal Health Workers in Wau, Western Bahr el Ghazal State, South Sudan. Scholars Journal of Agriculture and Veterinary Sciences, 4(11), 442-451. https://doi.org/10.21276/sjavs.2017.4.11.2

11. Musallam, I. I., Abo-shehada, M. N., \& Guitian, J. (2015). Knowledge, Attitudes , and Practices Associated with Brucellosis in Livestock Owners in Jordan. The American Journal of Tropical Medicine and Hygiene, 93(6), 1148-1155. https://doi.org/10.4269/ajtmh.15-0294

12. Ntirandekura, J., Matemba, L., Ngowi, H., Kimera, S., \& Karimuribo, E. (2018). Knowledge, perceptions and practices regarding brucellosis in pastoral communities of Kagera Region in Tanzania. Journal of Advanced Veterinary and Animal Research, $5(3)$, 343. https://doi.org/10.5455/javar.2018.e285

13. Obonyo, Mark, Gufu, W. (2015). Knowledge , Attitude and Practices towards Brucellosis among Pastoral Community in Kenya , 2013. INTERNATIONAL JOURNAL OF INNOVATIVE RESEARCH \& DEVELOPMENT, 4(10), 375-384. Retrieved from www.ijird.com

14. Rajala, E. L. (2016). Brucella in Tajikistan Zoonotic Risks of Urbanized Livestock in a Low-Income Country (Swedish University of Agricultural Sciences). Retrieved from https://pub.epsilon.slu.se/13851/\%0D

15. Samaha, H., Al-Rowaily, M., Khoudair, R. M., \& Ashour, H. M. (2008). Multicenter study of brucellosis in Egypt. Emerging Infectious Diseases, 14(12), 1916-1918. https://doi.org/10.3201/eid1412.071452

16. Shakurnia, A., Qasemzadeh, A., Afra, M., \& Kohshour, M. O. (2014). Sero-prevalence of brucellosis among blood donors in Ahvaz, Southwest Iran. Asian Pacific Journal of Tropical Disease, 4(S1). https://doi.org/10.1016/S2222-1808(14)60461-
8

17. Sofian, M., Safaeipour, L., Aghakhani, A., Sharif, M. R., Banifazl, M., Sharif, A., ... Ramezani, A. (2013). Screening of family members of patients with acute brucellosis in an endemic area of Iran. Iranian Journal of Microbiology, 5(3), 215-219.

18. Turgut, M., Haddad, F. S., \& De Divitiis, O. (2015). Neurobrucellosis: clinical, diagnostic, therapeutic features and outcome. Unusual clinical presentations in an endemic region. Neurobrucellosis: Clinical, Diagnostic and Therapeutic Features, 15(1), 1-182. https://doi.org/https://doi.org/10.1016/S14138670(11)70140-4

19. Warwick, C., \& Corning, S. (2013). Managing patients for zoonotic disease in hospitals. JRSM Short Reports, 4(8), 204253331349028. https://doi.org/10.1177/2042533313490287

20. Workalemahu, B., Sewunet, T., \& Astatkie, A. (2017a). Seroepidemiology of Human Brucellosis among Blood Donors in Southern Ethiopia: Calling Attention to a Neglected Zoonotic Disease. 96(1), 88-92. https://doi.org/10.4269/ajtmh.15-0702

21. Workalemahu, B., Sewunet, T., \& Astatkie, A. (2017b). Seroepidemiology of Human Brucellosis Among Blood Donors in Southern Ethiopia: Calling Attention to a Neglected Zoonotic Disease Seroepidemiology of Human Brucellosis among Blood Donors in Southern Ethiopia: Calling Attention to a Neglected Zoonotic Dis. The American Journal of Tropical Medicine and Hygiene, 96(1), 88-92. https://doi.org/10.4269/ajtmh.15-0702

22. Zhang, N., Zhou, H., Huang, D. S., \& Guan, P. (2019). Brucellosis awareness and knowledge in communities worldwide: A systematic review and meta-analysis of 79 observational studies. PLoS Neglected Tropical Diseases, 13(5), e0007366. https://doi.org/10.1371/journal.pntd.0007366 